I ssues of Fost ering I nnovati onal Engi neer s in a Technol ogy Ori ent ed Ent er pri se

\begin{tabular}{|l|l|}
\hline 著者 & Kunamot o Kei suke, Tomi sawa Osamu \\
\hline page r ange & $163-167$ \\
\hline year & $2006-09$ \\
\hline URL & ht t p: //hdl . handl e. net /10173/331 \\
\hline
\end{tabular}




\title{
Issues of Fostering Innovational Engineers in a Technology Oriented Enterprise
}

\author{
Keisuke Kumamoto and Osamu Tomisawa \\ Kochi University of Technology \\ Tosayamada, Kochi, Japan
}

\begin{abstract}
In this paper, we will discuss necessity, scout method and the training technique of engineers who will create innovations with a trend analysis of software industries. The criterion for finding human resources is depending upon the person who has her/his own strong interest say "the desire" about innovations. It is important that their cultivation should be worked out under the circumstance of daily job incorporated with their strong interest.
\end{abstract}

Keywords- Human Resource Cultivation, Innovations, Technology Management, Treatment for Personnel Affairs

\section{Introduction}

Ikujiro Nonaka has defined innovational people as a knowledge-creating crew which includes knowledge practitioners, knowledge engineers and knowledge officers. In this paper, we will use similar definition for innovative human resource as one which is supposed to play a role of the model proposed by him.

First of all we will point out that the reason of Japanese slumping economy in these days is possibly caused by less innovational activities in the wide area of industries. Then, we will address importance of acquisition and cultivation of innovative engineers to win over the severe competition of technology innovation among technology concentrated software enterprises. We will also discuss the possibility boundary of innovative creation in a software enterprise from the aspect of value-chain and value-net concepts.

Finally, we will try to propound a new model about the scout for innovative human resources and their cultivation related with SECI model by Nonaka

II. Issues of Technologically Oriented Enterprises A. Japan's Ailing Economy and Innovations

Figure 1 shows a comparison of total factor productivities in major countries. Total factor productivity means the broad conception that does not only include engineering 'technological innovation', but also includes the management innovation and the development of labor ability. Here, it is necessary to note that total factor productivity includes factors other than 'technological progress' such as scale economics

Consequently, we may make a judgment that the increasing rate of total factor productivity means the increasing rate of innovations under the concept of "New Combination" that Schumpeter propounded, although both are not strictly equal in several respects because they include some factor s of scale economics.
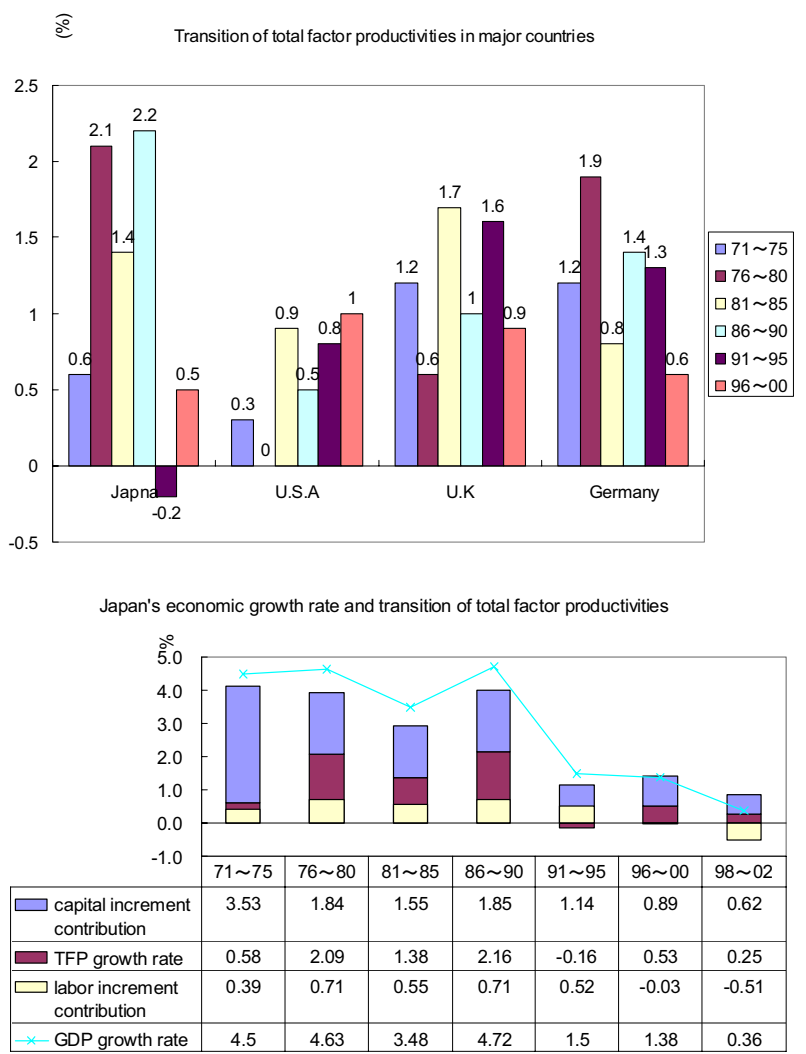

Figure 1 Japan's economic growth rate and transition of total factor productivities (Source: OECD statistics database '96)

Based on this assumption, we can tell that Japanese economy had gone very well until 1990 due to innovative activities in comparison to the growth rate of total factor productivities in major countries. But in 5 years after 1991, it showed negative economic growth rate, and the following years, innovations started to grew stagnant and it is feasible to understand that it should be related to the stagnation of economic growth rate.

\section{B. Issues of Software Enterprises}

The following is the general description of the chairperson's address appearing in JISA website. 
"Computers were initially translated into Japanese word that means electronic calculators but now they have changed to ICT (Information Communication Technology) from IT (Information Technology) because they were connected through networks. This dramatic change came true based on the remarkable technology progress in semiconductors, operating system, middleware, massive and high-speed data communications. But now, the world bends their steps toward ubiquitous and society needs high-reliability system that will contribute the infrastructure of economic society with taking advantage of these factors of advanced technology".

As stated above, software enterprises are required to develop extremely high-quality systems despite their scales are dramatically increasing and this is because their systems assume a role of the infrastructure of economic society. Therefore, software enterprises are daily required to change in development techniques such as improvement of project management capabilities and 'synchronous stabilization process' (2) which is adopted by Microsoft.

Moreover, software enterprises are required to adjust to situation that cannot be assumed in the traditional and conventional way of thinking. For example, we must handle issues related to the interface with radio technique, which is needed to become reality of ubiquitous and the adoption with built-in software, which is a new business field.

In that sense, we are facing critical issues to scout innovative engineers and to cultivate them, who can manage those situations.

\section{Innovation Area in a Software Enterprise}

2. Firstly, system product plan is defined according to the company's strategy. Then, business operations begin to introduce services to the market. After the acceptance of order, consultations to enhance competitive strength are carried out at the macro- and micro- levels and the overall picture of the system is formulated in order to develop.

After that, actual system developments begin and then following processes for the system will continue: basic designing, detail designing, formulation, transition to users and operation supports.

\section{B. Innovation Area in a Software Enterprise}

The main fields that need innovations in the development of systems are system product plan, solution plan, business models and basic design to the development. In the fields of system product plan, solution plan and business models; innovation is required to lead and to enhance the competitive advantage among users by the performance improvement of hardware or the progress of ITC technology. In the fields of basic design to the transition and operation supports, reduction of development period and quality improvement are required by the innovations for development techniques.

\section{Trend of Human Resource Management}

Scheme of human resource management has been different in three periods: from high economic growth period to bubble economy burst period, after bubble economy burst period to present days and now new age is about starting. Following figure indicates a roughly designed schematic diagram in the period of from high economic growth period to bubble economy burst period and after that. High economic growth period was that revenue and profits were both

\section{A. Value Chain in a Software Enterprise}

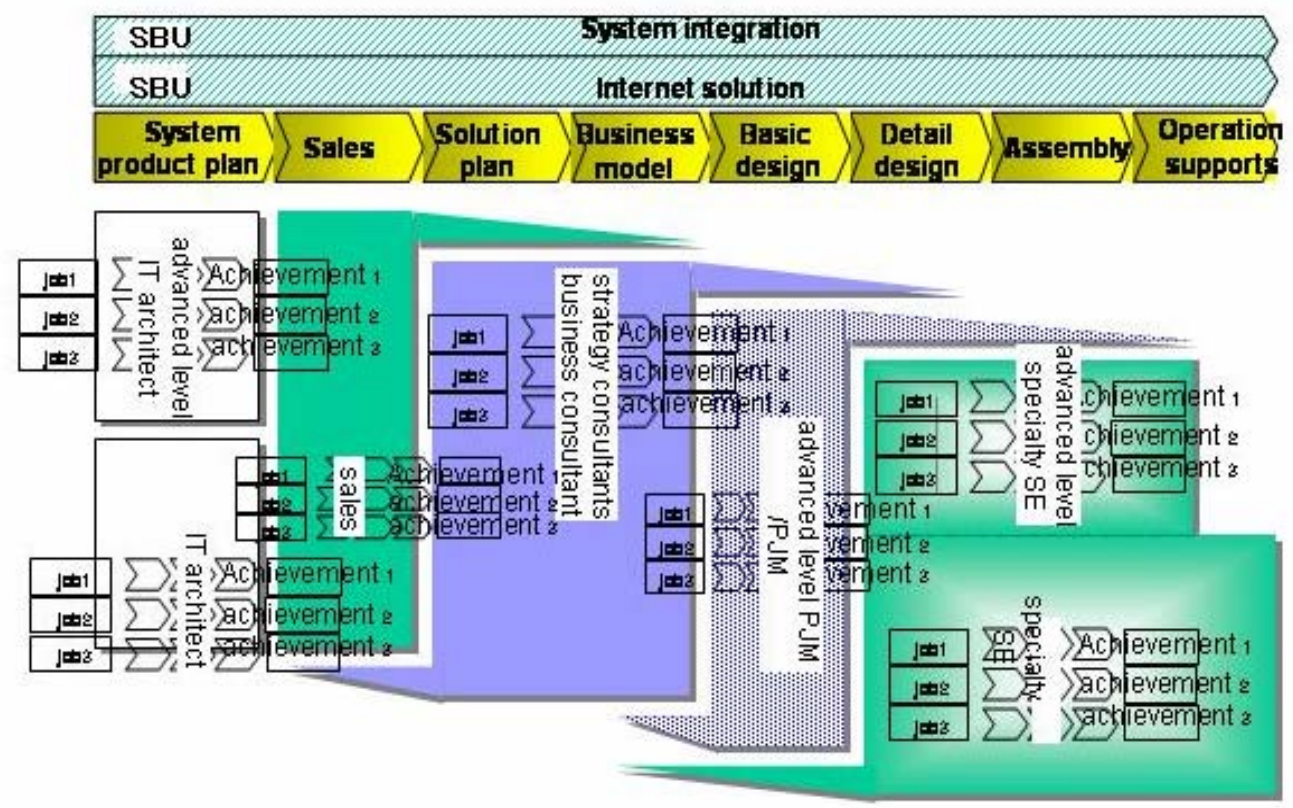

Figure 2 Value Chain of Software Company

Value chain in a software enterprise is as shown in Figure increasing. In this period, the origin of competitive strength 
was the operation strategy, which was mass production and mass marketing of high quality products with imitating models in Europe or the United States.
Against this demand, there were many enterprises that revised to the cultivation or treatment system by the human resource model that was provided by behavioral pattern on the basis of competency theory. Here, their basic concept was the market
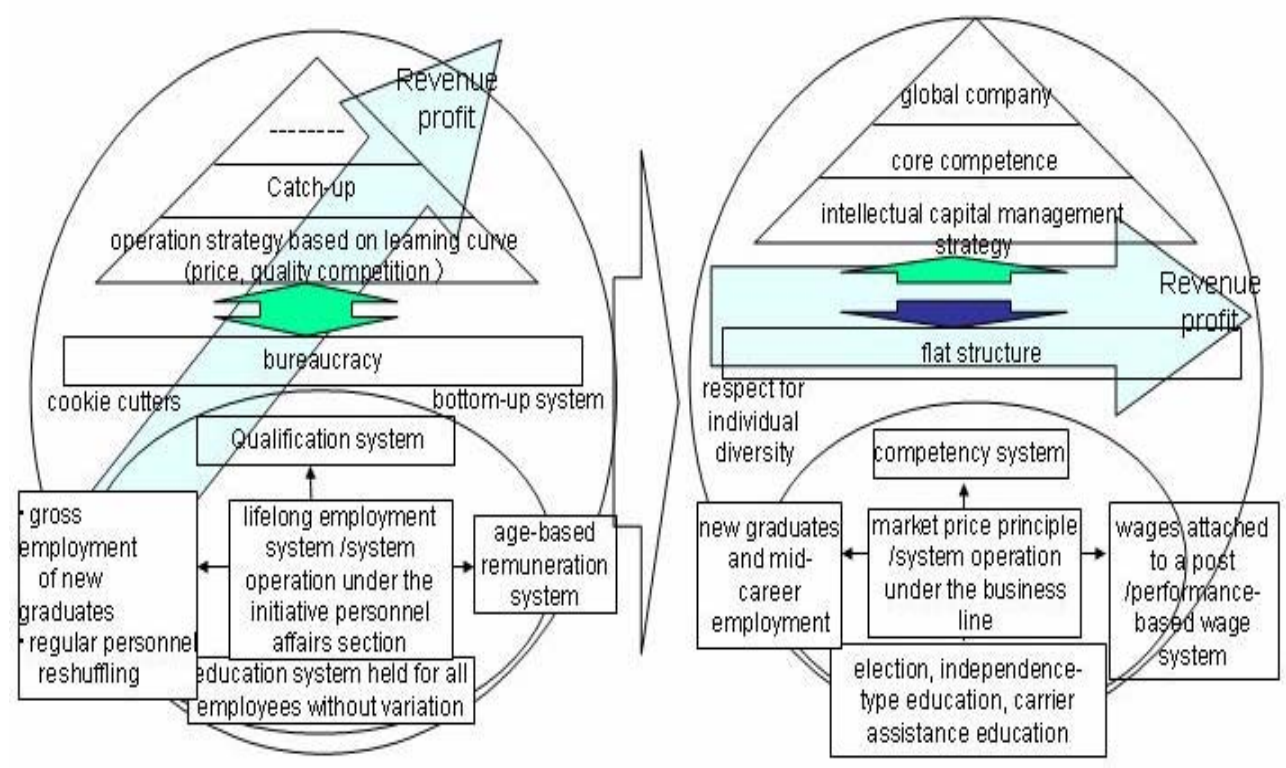

Figure 3. Change of human resource management

Therefore, the important point in human resource management at that time was to cultivate human resource who only work patiently according to plan as though they were cookie cutters without showing doubt the strategy and the business scheme of their enterprise.

For that purpose, according to the system operations of several employee management systems as the center such as lifelong employment system, salary increase system, position advancement system and personnel positioning system of which personnel affairs section had the power as an official authority, followings were worked out: 1. Age-based remuneration system that was premised on the assumption that the skill increases in proportion to the years of continuous employment. 2. Qualification system that clearly specified the aim of ability development. 3. Personnel and job relocation of employees and their skill development that responds to the business strategy as premises for lifelong employment system. Holding of education for ability development and management with dividing all the employees into several level groups. 4. Personnel acquisition according to the recruitment method that only the new graduates who seemed to easily become familiar with the organizational culture and the organizational climate. By these systems, enterprises patiently sought after human resources who shared the same values, high quality and cost reduction.

After the bubble economy burst, new personnel system was sought under the circumstances that revenue and profits were staying flat level or even decreasing. Consequently, they wanted to implement and manage a plan in consideration of efficient investment and short-term achievement because it was difficult to invest in lifelong human resources as it was so. price principle and the management of treatment system by a business line.

Moreover, they carried out as follows: The construction of the assessment system centering on tangible ability and achievements instead of the former assessment system even considered of their potential ability. The operation of education system has changed based on the necessity recognition about individual education with the improvement of individual carrier recognition instead of the former education system that was held for all the employees without variation. Outside human resources was employed to get quick starters to keep up with the rapid changes in the business environment and created new businesses. Thus, mid-level employees were said to be unwanted then the organization was made flat.

In this period, the fundamental idea of human resource management was that employees were resources that can be hired at the cost of the time and they can be laid off when they were unneeded. However, we can say that it did not completely have consistency with so called core competence management or intellectual capital management, which were the mainstream at that time.

Nowadays, according to the importance of innovations, they re-evaluated the strong interest say "the desire" of individuals about the enterprise or the business and also the importance of the imbalance on the basis of mid-level employees.

\section{Human Resource Model of Innovations}

In the field of innovation, Nonaka defined the correspondence between the SECI model and the human resource who performs it in his "Knowledge-Creating 
Company". Thus, in this section, we will propound a revised model of his theory after confirmation it.

\section{A. A Model that Nonaka Propounded}

The Nonaka's SECI model and human resource type who works in the scheme are shown in the figure as follows;

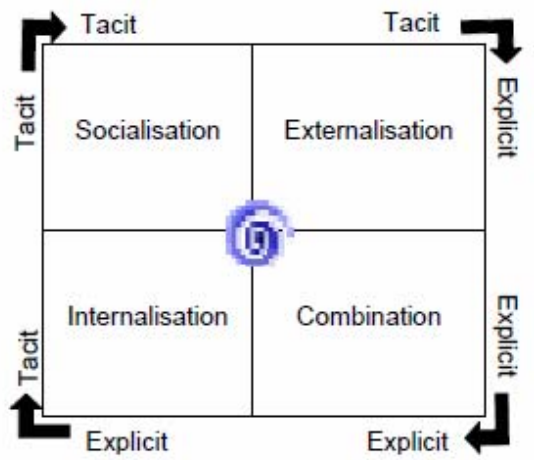

\begin{tabular}{|l|l|}
\hline knowledge practitioners & $\begin{array}{l}\text { forefront employees and middle } \\
\text { manager }\end{array}$ \\
\hline$<$ knowledge operator $>$ & $<$ treatment of invisible knowledge $>$ \\
\hline \multicolumn{1}{|c|}{$<$ knowledge specialis $\vdash>$} & $<$ treatment of formal knowledge $>$ \\
\hline knowledge engineer & middle manager \\
\hline knowledge officer & top manager \\
\hline
\end{tabular}

Figure 4. Nonaka's SECI model and the knowledge- creating crew

Figure 4 shows the needed talent definition of human resources that are defined in the model.

Nonaka propounded that knowledge practitioners must have strong commitment about converting the world depending on their high intellectual level and their own way of looking. They must also have various experiences outside their company, good conversation skill and a large heart to perform frank discussion with customers or co-workers at the office.

Knowledge engineer must have high-level project management ability, hypotheses formulation technique, technique integration ability, communication, a technique to assist someone to create images and verbalization using metaphor, ability to ferment the sense of trust among team member, ability to characterize future pathway by understanding history.

Knowledge officer must have ability to create knowledge vision to provide sense of direction to creative endeavors of knowledge in a company, ability to let project member know and understand about corporate culture that is the knowledge vision and the basis, ability to justify the quality of knowledge that was created on the basis of organization standard, mysteriously visceral ability to choose project leader without fail, decisive to create chaos by giving project team say enormously challenging target, technique to bring out the commitment from team members with thickly interaction, ability to manage command-and-control of entire system of organized knowledge-creating.

\section{B. Proposals of a New Model}

Software development functionally consists of project leader, project manager, leader and development member. Functionally, for instance, development of payroll calculation system, it often consists of functional development group such as monthly calculation, bonus calculation and annual adjustment, and development group of infrastructure such as network.

In Nonaka's innovation model, project leader corresponds to knowledge engineer. Although it can't be completely defined, project manager, functionally divided leader and project member correspond to knowledge operator or knowledge specialist In this formation, super programmer who corresponds to a knowledge operator as a project member is not necessary to be directly connected with the outer world. After learning basic skill by books or in-house training, she/he can contribute to provide innovation as tacit agreement by her/his invisible know-how through private study and duties. Nonaka wrote about knowledge operator in his book, "Since their duties are carried out at forefront of their business and they continuously and directly touch the outer world, they can access the latest information on development of market, technology and competition".

"Almost all of them are forefront employees or line managers so they situate at the nearest from the actual business".

At this point, there is a discrepancy in Nonaka's description that a knowledge operator as a super programmer is not necessary to be directly connected with the outer world. So in this chapter, this type of human resource is defined as a knowledge operator and we try to propound a new human resource model.

\section{Discovery of Innovative Human Resource and Their Treatment}

Firstly, we clearly specify motivation advancement measures that are adapted to all kinds of occupation and duties, which will be premised on the matters about the discovery of innovative human resource and their treatment.

It will be worked out by ensuring linkages to the transparency of valuation systems. The operation system should be designed that the employee could feel "My duties are duly appreciated and I am satisfied to be treated". By this way, the employee could enhance and keep up her/his motivation. The employee who will practice innovations is carrying out her/his business with thinking about the existence value of her/his own. The actualizing is the first matter with high priority. So the issue is not always related with the regardless of the size of salary nor the treatment, but the environment whether employees can actualize their existence value say "the desire" or not.

For this reason, the company is needed to provide the environment where "the desire" can be actualized for innovation human resources. In other words, it is important that the environment should be in the system that innovation human resources could turn in their report directly to the head 
of the enterprise, not to the manager of the business who is in charge of the budget, the authority of final decision and the existing business

As Drucker propounded, valuation should not be judged on the basis of common standard, but should be judged on the basis of individual standard.

Also, the innovation engineer should find out if the individuals have their own strong interest when they think about their scout and the cultivation.

However, in order to set the individual environment as stated above, there are some cases that the person in charge is liable to ignore even the rules set by the company as though she/he carries out the duties with her/his particular hobbies.

For such occasions, the person in charge must be checked if she/he persistently has advanced sense of ethics to keep the business as a person of an enterprise.

And the innovation engineer should be needed to provide the matters that the market demands.

In such reasons, the innovation engineer must have the ability of hypotheses formulation technique, and also she/he must have the communication ability to bring out the invisible know-how of team members and the ability to let the members recognize difficult commitments. To develop these abilities, induction course or OJD are required.

As the innovation operators, several kinds of human resources are demanded. They are such as programmers, marketers and the consultants for management strategy etc.So, the way of cultivation is different depending on its type. The matter that should be emphasis to say here is that the programmer is not always connected with the outer world.

The person should be evaluated that she/he has know-how (invisible knowledge), which was accumulated by duties on the basis of the knowledge that she/he personally learned even by indirectly. And innovation operators should sustain the environment to accumulate their know-how through several times of trial-and-error process without pursuing only efficiencies.

\section{Conclusion}

The origin of the competitive strength among software industries is exactly due to human resources. And technological innovations such as IT skill are intensified. On the other hand, knowledge about the theory of management such as management strategy theory is also demanded to propose to enhance competitive strength of enterprises. It is impossible that one employee manages all of this knowledge. So it is important to scout and cultivate innovation human resources at each field dividing into human resource types as stated in this paper.

The aim of this paper is that all kinds of human resource types are not always directly connected with the outer world. And if there are individual desire and career oriented mind, there will also be know-how (invisible knowledge), which is accumulated by duties through the repetitive trial-and-error processes of an individual person. Further, to scout and cultivate these human resources, it is important to check if the individuals have their desire and also is important to check if they have advanced sense of ethics. However, there is no discovering of validation method so far to check the evidence whether the person has advanced sense of ethics or not.

Lastly, we specified that it is important to provide the environment that the person can delightfully perform duties that she/he wants to keep and to sustain their higher motivation and it is never due to the issue of the financial or the status.

\section{References}

[1] Ikujiro Nonaka \& Hirotaka Takeuchi, "The Knowledge-Creating Company", Oxford University Press, 1995.

[2] Michael Cusumano, "The business of Software", Free Pr, 2004

[3] Ikujiro Nonaka \& Hirotaka Takeuchi, "The Knowledge-Creating Company", Oxford University Press, 1995. 